\title{
The Difference between Performance Levels on the Adaptive Behavior Scale for Students with Mild Intellectual Disabilities Who are included in Public Schools Compared to Those Enrolled in Special Education Centers in Amman Governorate
}

\author{
Dr. Abeer Youesf Alsafran \\ Special Education Teacher at Ministry of Education, Kuwait City \\ Dr. Mirvat Youesf Amireh \\ Special Education Counselor at Ministry of Education, United Arab Emirates
}

\begin{abstract}
The study aimed at identifying the differences in the levels of adaptive behavior among students with intellectual disabilities in public schools and students in special education centers. The population of the study consists of students with mild intellectual disabilities in public schools, and students with minor intellectual disabilities in special education centers. The sample consists of (50) included students at schools, and (50) students enrolled in special education centers. To achieve the purposes of the study, the adaptive behavior teachers' image (6-15 years) was used. It was localized to its Jordanian image by (Al Ali, 2010), and it has the required psychometric features.dThe results showed that the performance level on the Adaptive Behavior Scale of included students in public schools from their teachers' point of view was average. The level of performance of students in special education centers on the same scale was low. The study also found that there were significant statistical differences at the level $(0.05 \geq \alpha)$ for the performance of students on the scale according to variable type school, where the difference was in favor of public schools when compared to the centers in the total degree In all domains, with the exception of "health and safety" and "leisure and play management" where the difference was in favor of special education centers.
\end{abstract}

Keywords: Adaptive Behavior, People with mild Intellectual Disabilities, Public Schools, Special Education Centers.

DOI: $10.7176 / \mathrm{JEP} / 10-30-01$

Publication date:October $31^{\text {st }} 2019$

\section{Introduction}

Mankind is one of God's most outstanding creatures and most of all is the human possession of unlimited abilities that open up wide horizons for learning, understanding and production in life. Hence, it's worthwhile to have an understanding of human learning and developing in the different domains which proves itself as of great importance. Since people with disabilities are part of society, many countries around the world tend to pay attention to them, care for them and provide all health, social and educational services to them, just as any other members of society. This stems from the belief that society should exploit their abilities to the maximum and believing that this is their right, especially after adopting the specified laws, legislation and conventions that guaranteed them this right. This is the foundation from which people with disabilities will move towards positive social growth and successful adaptive social behavior (Felce and Perry, 2009)

The philosophy of education has changed over time from special education to public education. Part of this shift is founded by the idea that students with disabilities must be educated in the least restricted environments. The children inclusion in the past few decades has been enhanced by legislation that has supported the integration of individuals with disabilities in society and institutions of education significantly. This was supported by the application of the IDEA Act. The implementation of IDEA act contributed was not only to the increase in the number of students integrated into public schools, but also to the provision of more services within the regular classroom (AL-quraini and Gut, 2012). At the national level, Jordan was one of the first Arab countries to sign the International Convention in 2007, declaring its commitment to implementing the provisions of the Convention in order to achieve its objective and goal of protecting the rights of persons with disabilities and ensuring the full enjoyment of human rights and fundamental freedoms. The educational reform that followed included services and educational programs provided by the Ministry of Education and the Ministry of Social Development which adopt the principle "education for all" and accept the categories of students with disabilities in their schools and centers and put each of these categories in suitable programs that meet their needs (Al-saree', 2014).

With the emergence of numerous studies on students with intellectual disabilities, the concept of adaptive behavior has acquired a significant interest in their diagnostic and training services. The adaptive behavior measuring and training has become an integral part of the services provided to students with intellectual 
disabilities (Santos, et al., 2014). This principle stems from the fact that the problems facing students, parents caretakers' are not limited to educational, but rather extend to their adaptive behavior which is an important basis in their interaction with the environment and the performance of their social duties in order to properly integrate into society. In the Ajami \& Assif study (2013), parents of individuals with intellectual disabilities have positive results regarding the social domain of their children. The integration of their children with intellectual disabilities helps them develop socially and psychologically, and allows them to form friendships and increase their socialization.

Based on the aforementioned, the adaptive behavior skills are critical to integrating students with intellectual disabilities into mainstream education programs that are closely related to the person's inclusion in everyday life. Otherwise, this will be a major obstacle to independent and stable life (De la Vega, et al., 2013). Hence, the study of the effect of this integration on their adaptive behavior compared to those who receive services in isolated places is of great importance in special education sciences (Ashby, 2010). In its modern concept, humanities focus on the fact that the school is a special environment that represents a real integrated life for students. Not only it provides academic services to students, but also plays a role in the development of the various behavioral components that enrich their life and enable them to contribute to the development of their abilities. Now, people with intellectual disabilities in public schools appear stronger, after a period of predominant tendency towards isolation, exclusion and discrimination (Ashby, 2010).

Theoretical literature indicated that the adaptive behavior of students with intellectual disabilities includes social skills: social relations, social responsibility, self-esteem, social problem solving, and follow-up instructions (Felce and Perry, 2009). In a comparative study of adaptive behavior among students with intellectual disabilities who are integrated into public schools compared to those in private centers, the results of the study conducted by (Bakhsh, 1999) in Saudi Arabia indicate that the effectiveness of the method of integration in improving self-concept and adaptive behavior is more common among girls with intellectual disabilities among other regular and non-disabled school girls in school. This leads to their feeling that they are not isolated from their peers and are integrated into the normal school community, while the isolation of females with intellectual disabilities within private institutions has led to a significant reduction in their perception of themselves and their adaptive behavior.

Sharif et al. (2015) studied the development of belonging in children with mild intellectual disabilities in the light of isolation and inclusion systems, they conducted a study on the detecting inclusion and segregation effects in the development of belonging. The results of the study showed statistically significant differences between the children average grades in the development of belonging For the benefit of the inclusion group system versus the other group in the isolation system. In order to study the social sphere as one of the domains of the Adaptive Behavior Scale after years of enrollment for students with mild intellectual disabilities in the comprehensive integration programs and isolated programs, (Fisher and Meyer, 2002) conducted a study aiming at evaluating the level of development and social efficiency and compare the results of the two groups, The results showed statistically significant differences for the inclusion group on the scale. They achieved higher social efficiency scores compared to the isolated group, which achieved few social gains.

In a study conducted by Omigbodun and Adeniyi (2016) to examine the impact of classroom-based intervention on social skills of students with intellectual disabilities, and to identify the impact of social skills training for students with intellectual disabilities in a school for people with intellectual disabilities. The results of the study indicate that the social skills of students with intellectual disabilities who participated in this study have improved significantly. Hardiman, et al. (2009) conducted a study aimed at comparing the social efficiency of children with intellectual disabilities in the comprehensive inclusion classes versus students in the isolated classes. The results of the study showed that children with intellectual disabilities in comprehensive schools did not differ in their performance on the measure of Adaptive Behavior Scale compared to separated children in schools on most domains of the scale related to social competence. Larson et al. (2012) conducted a longitudinal study, which reviewed (43) American studies to assess the results of social competence and adaptive behavior of persons with intellectual and developmental disabilities who moved from private institutions to comprehensive integration and community life that were published between 1977-2010. The results of the study showed that people who moved to life in society showed statistically significant improvement in adaptive behavior skills compared with those who remained in private institutions, while only (3) studies showed a decrease in adaptive behavior that found statistical significance.

In addition to adaptive behavior of students with mental disabilities, social skills also include conceptual skills in language, literacy, time, numbers, and self-direction (Felce and Perry, 2009). In this regard, Jarrar (2012) points out that when choosing the appropriate educational alternative to integrate a student with a mild intellectual disabilities, it is necessary to determine how the staff can work in either a resource room, a special class in a public school or will be included in public classes throughout the day with this is undoubtedly determined by the student with intellectual disabilities and capabilities, as s/he will receive the special education program in one of these alternatives, and will be subject to the educational program. Research has indicated the 
importance of moving to school for children with intellectual disabilities and their families. Successful student adaptation to school is likely to be influenced by several factors, most notably academic, social and cognitive competencies. Children with intellectual disabilities may be at increased risk and prone to early school difficulties partly because of deficits in their cognitive and adaptive behaviors (McIntyre, et al., 2009). On the cognitive skills side, Vianello and Silvia (2011) conducted a study whose results indicated that the presence of students with intellectual disabilities, rather than the private lessons, can enhance cognitive and conceptual aspects and social development. In addition, attending regular courses can allow students with intellectual disabilities to reach results Higher in school and a higher level of adjustment than we expected on the basis of his performance on intelligence tests. The results also indicate that the presence of students with intellectual disabilities in a normal classroom promotes better psychological development, especially from the social point of view, (for example: friendship, social acceptance, and participation in school concerts, and improve its ability to adapt).

In order to compare the academic efficiency and academic performance of students with mild intellectual disabilities combined with the performance of students in isolated private centers, the results of Vishwakarma and Pal (2016) showed that the average performance of students in academic skills in inclusive schools is better than that of students in private centers. In order to detect the differences in adaptive behavior skills represented by language skills and social interaction among students with mild intellectual disabilities integrated in public schools compared to students in special education centers,(Al-Akhzmi et al., 2013) conducted a study in Oman. The results of the study showed statistically significant differences in the language and communication skills of the two included students, and in all the social interaction skills that is attributed to the inclusion.

The literature indicated that the skills of self-direction and self-determination of the individual with intellectual disabilities are influenced by environmental factors, including living or working settings, which play several internal factors in the individual, such as IQ, social skills and adaptive behavior, They have selfdetermination, social capacities and environmental living conditions that have been shown to positively affect the adaptive behavior of the individual with disabilities. Nota et al. (2007) also noted that individuals enrolled in inclusive and comprehensive schools differed from those treated in special centers as they showed greater independence and self direction in their daily activities, and the basic socialization skills related to membership in groups were higher than those in isolated private centers.

Buckley et al. (2009) conducted a study to compare the achievements of students with Down Syndrome who are educated in the general classroom with peers who are enrolled in special education classes to measure progress in communication skills, literacy, socialization, daily living skills and behavior. She noted progress in all domains except the domain of communication were not for the benefit of students enrolled in private classrooms, and that there were no significant differences in the results of daily living skills or social upbringing between students in the general classes and those in the special education classes. There were significant gains in the communication skills, expressive writing and the literate reading of learners in general classrooms. general classroom were proven to have less behavioral difficulties for these students.

The Adaptive Behavior Scale measuring comprise evaluating the adaptive behavior of individuals with intellectual disabilities in relation to their level of practical skills including: daily living skills, occupational skills, health care, travel and mobility, public safety, money use, phone use (Felce and Perry, 2009). In a study by (Lanfranchi and Vianello, 2008) on children of Bradley Willy syndrome, children showed superiority in adaptive behavior (ie, communication and daily life skills), where there were many cases of excellence for students with intellectual disabilities in the domains of adaptive behavior and the authors attributed this excellence to the positive results of the integration of most students with intellectual disabilities in schools in Italy.

Woolf et al. (2009) also conducted a study to measure the levels of adaptive behavior among adults with intellectual disabilities, and their relation to their levels of independence, their relationship with the group, and the actual levels of work and independence of their living. The results of the domain study showed that participants who showed higher levels of adaptive behavior generally had more independent levels of work and living. Jones, et al., 2008 also conducted a study of attitudes of community development services staff to integration issues for individuals with intellectual disabilities. The researchers emphasized incurred changes in the inclusion of people with intellectual disabilities in the community which included independent living conditions and support of their living conditions (physical and social) to be regular and permanent. The researchers stressed the importance of enhancing the personal skills and social image of people with intellectual disabilities.

Alwell and Cobb (2006) analyzed career curricula for post-developmental high school students who were not active in the integration classes, but in places ranging from special classes to intellectual special centers. The researcher present a proposed curriculum that includ skills such as purchasing skills, budgeting skills, money handling skills, entertainment skills, housekeeping skills, cooking skills and food preparation. The results of the study indicated that students with intellectual disabilities in special centers progressed on the domains of the proposed curriculum despite not being exposed to the integration program. 


\section{Problem of the study and its questions}

The Hashemite Kingdom of Jordan is one of the first Arab countries to sign international treaties that affirm the support and entitlement of students with intellectual disabilities in less restrictive environments within public schools. At the same time, however, it is still one of the countries with many centers providing services to students in isolated environments that serve students away from public schools for one reason or another, and for the fact that intellectual disabilities have clear impact on the adaptive behavior of people with intellectual disabilities. The current research problem is trying to find out the levels of adaptive behavior for students with mild intellectual disabilities in public schools compared to students with mild intellectual disabilities in special centers, and to find out the difference in the various domains of the measure of adaptive behavior among them that may have an impact on making decisions by including these students, whether by parents or legislators and decision-makers.

The study therefore seeks to answer the following questions:

1. What is the level of performance of students with intellectual disabilities in public schools on the Adaptive Behavior Scale from their teachers' point of view?

2. What is the level of performance of students with intellectual disabilities in special education centers on the Adaptive Behavior Scale from their teachers' point of view?

3. Are there statistically significant differences in the performance levels of students with intellectual disabilities on the Adaptive Behavior Scale with reference to the school type variable (included in public schools and those in special education centers?

\section{Importance of studying}

Due to the increasing tendency to enroll students with mild intellectual disabilities in public schools due to the increasing interest in their integration programs in public and private public schools, with increasing attention to the students' adaptive behavior levels and their impact on their inclusion with their teachers and peers at the Arab and Jordanian levels In schools, it was necessary to study the differences in the level of adaptive behavior of the integrated students compared to those in special centers. This study comes in handy due to the lack of studies on this subject at the Arab and Jordanian levels, with the aim of enriching the Special Education library with studies in this domain.

\section{Terminology of study}

Adaptive Behavior: Collecting the conceptual, social and practical capacities that a person has to work effectively on his daily living (Dela Vega, et al., 2013).

Intellectual Disability: The American Association on Intellectual and Developmental Disabilities defined it in 2008 as a disability characterized by a marked decline in both cognitive performance and adaptive behavior represented by conceptual, social, adaptive and practical skills. This disability appears before the age of 18 (Khatib, 2010).

Mild Intellectual Disabilities: One of the intellectual disabilities classifications is governed by IQ, which accounts for about $80 \%$ of all persons with intellectual disabilities in any society. Their IQ is between 55-70 degrees on intelligence tests and two negative point deviations from the average normal distribution curve of intellectual ability (Khatib, 2010).

Public Schools: A public institution that provides students and young people with knowledge, education, and teaching of social and religious facts, knowledge and values, and ways of working and thinking. It is a building in which students learn reading, writing, mathematics, science, studies, and various other sciences (Nasser, 2004). Special Education Centers: These centers have emerged as a reaction to criticisms of full residence centers. Many of these centers run training almost until midday. During this period, individuals with disabilities receive educational and social services. These centers help keep people with disabilities within her/ his family in a natural atmosphere (Khatib, 2010).

\section{Community and Sample of the study}

The study population consists of students with intellectual disabilities from eight public schools and three private education centers in the capital Amman governorate, geographically distributed in the west, north, south and east of the capital Amman.

A group of students was selected using the cluster sample method. The sample consisted of 100 students with a mild intellectual disabilities ranging from 6 to 15 years. The sample was divided into 50 students who received their education in public schools, the other (50 students) group received their training in special education centers. 
Table (1)

Distribution of study sample

\begin{tabular}{|l|l|l|l|}
\hline \multirow{4}{*}{$\begin{array}{l}\text { Education } \\
\text { Type }\end{array}$} & public schools & 50 & $50 \%$ \\
\cline { 2 - 4 } & $\begin{array}{l}\text { special education } \\
\text { centers }\end{array}$ & 50 & $50 \%$ \\
\cline { 2 - 4 } & total & 100 & $100 \%$ \\
\hline \multirow{4}{*}{ Sex } & male & 52 & $52 \%$ \\
\cline { 2 - 4 } & female & 48 & $48 \%$ \\
\cline { 2 - 4 } & total & 100 & $100 \%$ \\
\hline \multirow{4}{*}{ Age } & less than 6 to 9 & 51 & $51 \%$ \\
\cline { 2 - 4 } & 9 to less than 12 & 35 & $35 \%$ \\
\cline { 2 - 4 } & 12 to 15 & 14 & $14 \%$ \\
\cline { 2 - 4 } & total & 100 & $100 \%$ \\
\hline
\end{tabular}

\section{Determinants of the study}

The study sample was selected from students with mild intellectual disabilities who ranged from 6 to 15 years old in public schools and in special education centers in the capital Amman Governorate.

\section{Instrument}

The main instrument used to achieve the current study objectives was:

The Jordanian image of Adaptive Behavioral Assessment System in its second edition (ABAS-II, 2003): The image of teachers for the age groups (6-15 years) which was localized by Al-Ali (2010) in Jordan. The scale consists of 136 articles covering three sub-domains of adaptive behavior. These articles have been included in a number of sub-domains, namely:

1- Conceptual Skills: they include communication skills, academic skills, self-direction skills.

2- Social skills: they include social skills, leisure and play management skills.

3. Practical skills: they include self-care skills, home life skills, community skills, health and safety skills, professional skills.

\section{Purpose of the study}

The study aimed at identifying the differences in performance on the domains of adaptive behavior in children with intellectual disabilities who are integrated in public schools compared to students in special education centers in the capital Amman governorate.

\section{Results}

This part of the study includes a presentation of its findings by answering its questions, which were as follows: Question 1: What is the level of performance of students with mild intellectual disabilities integrated in public schools on the Adaptive Behavior Scale from the point of view of their teachers?

To answer this question, the arithmetical averages and standard deviations of the level of performance of students with mild intellectual disabilities who are included in public schools were calculated on the Adaptive Behavior Scale from the perspective of their teachers in general and each domain of the study instrument, cf. Table 2.

Table (2)

averages, standard deviations, and grades for the performance level of students with mild intellectual disabilities included within public schools on the Adaptive Behavior Scale from the point of view of their teachers, arranged in descending order

\begin{tabular}{||l|l|l|l|l|l|}
\hline \hline no & domain & average & deviation & grade & level \\
\hline 7 & Self-care & 2.76 & 0.74 & 1 & average \\
\hline 1 & communication & 2.48 & 0.59 & 2 & average \\
\hline 2 & community skills & 2.45 & 0.90 & 3 & average \\
\hline 6 & leisure and play management & 2.33 & 0.78 & 4 & average \\
\hline 4 & school life & 2.27 & 0.76 & 5 & average \\
\hline 9 & Socialization & 2.22 & 0.75 & 6 & average \\
\hline 8 & self-direction & 2.20 & 0.67 & 7 & average \\
\hline 5 & Health and safety & 1.85 & 0.81 & 8 & low \\
\hline 3 & Academic & 1.55 & 0.53 & 9 & low \\
\hline total grade & 2.27 & 0.49 & average \\
\hline \hline
\end{tabular}


Table 2 shows that the level of performance of students with mild intellectual disabilities included within public schools on the Adaptive Behavior Scale from the point of view of their teachers was average. The mean was 2.27 and the standard deviation was (0.49). averages ranged from (2.76-1.55). "Self-care" came in first with an average of 2.76 and a standard deviation of (0.74) with an "average" score. In the second position, the domain of communication was an average of 2.48 and a standard deviation of (0.59) with an "average" score. "Community skills" came in the third position with (2.38) and a standard deviation (0.78) with "average" score. In the fifth position, the domain of "school life" scored an average of (2.27) and standard deviation was (0.76) with an "average" score. In rank six, the "socialization domain" scored an average of (2.22) and a standard deviation of (0.75), with an "average" score. In rank seven, the domain of "self-direction" averaged at (2.20) and a standard deviation of (0.67) and "average" score. At the eighth level, the domain of "health and safety" scored an average of (1.85) and a standard deviation of (0.81) and "low" score. The last domain "Academic" scored (1.55) and a standard deviation (0.53) and "low" score.

Question 2: What is the level of performance of students with mild intellectual disabilities who receive training in special education centers on the Adaptive Behavior Scale from their teachers point of view?

To answer this question, the averages and standard deviations of the level of performance of students with mild intellectual disabilities in special education centers were calculated on the Adaptive Behavior Scale from the point of view of their teachers in general and in each sub domain of the study instrument.

Table (3)

averages, standard deviations and levels of performance of students with mild intellectual disabilities at special education centers on the Adaptive Behavior Scale from the point of view of their teachers in descending order

\begin{tabular}{|l|l|l|l|l|l||}
\hline no & domain & average & standard deviation & rank & level \\
\hline 6 & Leisure and play management & 2.62 & 0.78 & 1 & average \\
\hline 5 & Health and safety & 2.25 & 0.63 & 2 & average \\
\hline 7 & Self-care & 2.22 & 0.91 & 3 & average \\
\hline 1 & communication & 2.05 & 0.74 & 4 & average \\
\hline 4 & school life & 1.92 & 0.89 & 5 & low \\
\hline 2 & community skills & 1.89 & 0.77 & 6 & low \\
\hline 8 & self-direction & 1.83 & 0.78 & 7 & low \\
\hline 9 & Socialization & 1.73 & 0.80 & 8 & low \\
\hline 3 & Academic & 1.36 & 0.46 & 9 & low \\
\hline overall rank & 1.87 & 0.67 & average \\
\hline
\end{tabular}

Table (3) shows that the students level of performance with mild intellectual disabilities in special education centers on Adaptive Behavior Scale from the point of view of their teachers was low. The mean was (1.87) and the standard deviation was $(0.67)$ and the averages ranged from $(1.36-2.68)$. "leisure and play management" came in the first place with an average of (2.70) and a standard deviation of (0.78) and an average level. In the second place, the domain of "health and safety" was (2.25), a standard deviation at (0.63), and average level. At the third place, the domain of "self-care" scored (2.22) and a standard deviation of (0.91), and average level. In the fourth place came the domain of "communication" with an average of (2.05), a standard deviation (0.74) and an average level. (0.89) with low level. In the sixth place, the "community skills" came with an average of (1.89) and a standard deviation at (0.77) and a low level. In the seventh place, the domain of "self-direction" came with an average of (1.83) and a standard deviation of (0.73) with low level. At the eighth place, the "socialization" came with an average of (1.73) and a standard deviation of (0.80) at a low level. The "academic domain" came in the final place with average of (1.36) and a standard deviation (0.46) at a low level.

Question 3: Are there statistically significant differences in the performance levels of students with Mild Intellectual disabilities on the Adaptive Behavior Scale due to the school type variable (included in public schools and those in special education centers)?

This question was answered as follows:

A calculation of averages and standard deviations of the level of performance of students with mild intellectual disabilities were performed following the Adaptive Behavior Scale and based on schooling variable (included into public schools and those in special education centers) and t-test is also shown in Table 4. 
Table (4)

averages and standard deviations of the level of performance of students with mild intellectual disabilities on the Adaptive Behavior Scale and the t-test, based on school type variable (included into public schools and those in special education centers)

\begin{tabular}{|c|c|c|c|c|c|c|}
\hline domain & school type & no & average & $\begin{array}{l}\text { standard } \\
\text { deviation }\end{array}$ & $\begin{array}{l}\mathrm{T} \\
\text { value }\end{array}$ & $\begin{array}{l}\text { significance } \\
\text { value }\end{array}$ \\
\hline \multirow[b]{2}{*}{ communications domain } & public school & 50 & 2.48 & 0.59 & 3.213 & $* 0.002$ \\
\hline & $\begin{array}{l}\text { special education } \\
\text { centers }\end{array}$ & 50 & 2.05 & 0.74 & & \\
\hline \multirow{2}{*}{$\begin{array}{l}\text { Domain of community } \\
\text { skills }\end{array}$} & public school & 50 & 2.45 & 0.90 & 3.342 & $* 0.001$ \\
\hline & $\begin{array}{ll}\text { special education } \\
\text { centers }\end{array}$ & 50 & 1.89 & 0.77 & & \\
\hline \multirow[t]{2}{*}{ Academic } & public school & 50 & 1.55 & 0.53 & 1.926 & $* 0.053$ \\
\hline & $\begin{array}{l}\text { special education } \\
\text { centers }\end{array}$ & 50 & 1.36 & 0.46 & & \\
\hline \multirow[t]{2}{*}{ school life } & public school & 50 & 2.27 & 0.76 & 2.083 & $* 0.040$ \\
\hline & $\begin{array}{l}\text { special education } \\
\text { centers }\end{array}$ & 50 & 1.92 & 0.89 & & \\
\hline \multirow[t]{2}{*}{ Health and safety } & public school & 50 & 1.85 & 0.81 & 3.410 & $* 0.001$ \\
\hline & $\begin{array}{l}\text { special education } \\
\text { centers }\end{array}$ & 50 & 2.25 & 0.63 & & \\
\hline \multirow{2}{*}{$\begin{array}{l}\text { leisure and play } \\
\text { management }\end{array}$} & public school & 50 & 2.33 & 0.78 & 2.952 & $* 0.004$ \\
\hline & $\begin{array}{ll}\text { special education } \\
\text { centers }\end{array}$ & 50 & 2.62 & 0.78 & & \\
\hline \multirow[t]{2}{*}{ Self-care } & public school & 50 & 2.76 & 0.74 & 3.264 & $* 0.002$ \\
\hline & $\begin{array}{l}\text { special education } \\
\text { centers }\end{array}$ & 50 & 2.22 & 0.91 & & \\
\hline \multirow[t]{2}{*}{ self-direction } & public school & 50 & 2.20 & 0.67 & 2.518 & $* 0.013$ \\
\hline & $\begin{array}{l}\text { special education } \\
\text { centers }\end{array}$ & 50 & 1.83 & 0.78 & & \\
\hline \multirow[t]{2}{*}{ Socialization } & public school & 50 & 2.22 & 0.75 & 3.171 & $* 0.002$ \\
\hline & $\begin{array}{l}\text { special education } \\
\text { centers }\end{array}$ & 50 & 1.73 & 0.80 & & \\
\hline \multirow[t]{2}{*}{ Total } & public school & 50 & 2.27 & 0.49 & 3.429 & $* 0.001$ \\
\hline & $\begin{array}{l}\text { special education } \\
\text { centers }\end{array}$ & 50 & 1.87 & 0.67 & & \\
\hline
\end{tabular}

The results in Table (4) indicate that there are statistically significant differences at $(0,05 \leq \alpha)$ in the level of performance of students with mild intellectual disabilities on the Adaptive Behavior Scale according to the school type variable (included into public schools and those in special education centers) based on calculated (T) which gave (3.429) at (0.001) marker in favour of public school group compared to those in special education centers in the total grades and in all of the sub levels as per the shown averages, excluding the domain of "health and safety" and "leisure and play management". The difference in these two domains was in favor of Special education centers group when compared to public schools as evidenced by the higher averages.

\section{Discussion}

The study aimed at identifying the differences in performance on the domains of adaptive behavior in children with mild intellectual disabilities who are included at public schools compared to students in special education centers in the capital Amman governorate. The following is a review of the findings of the study and its main recommendations as follows:

- The first question which inquires about performance level of students with mild intellectual disabilities included in public schools on the Adaptive Behavior Scale from their teachers point of view?

To answer this question, the arithmetical averages and standard deviations of the level of performance of students with mild intellectual disabilities included in public schools were calculated on the Adaptive Behavior Scale from the point of view of their teachers in general and for each sub domain of the study instrument. The scores in these domains gave medium and low results as averages were between (1.55-2.76). The highest domain was achieved by "personal care" with average. The second level was the domain of "communication" with average. In the third rank was the domain of "community skills" with average. In the fourth rank came the domain of "leisure and play management" with average. In the fifth rank came the domain of "school life" with 
average. In the sixth rank was "socialization" with average level. In the seventh rank came the domain of "selfdirection" with average level. In the eighth rank came the domain of "health and safety" with low level.

It is noticeable in this conclusion that the included students in public schools performed better than those in special education centers on the Adaptive Behavior Scale. This may be due to the fact that students who have been integrated into public schools have had greater opportunities than their counter group by trying to imitate their fit colleagues, as they are provided with more focus from teachers more than others which makes the environment and educational tools a reason for change and development in their performance. This may be attributed to the fact that the student with intellectual disabilities who are included in public schools over time become familiar with teacher instructions, dealing with peers that allow them to rely on independent skills more in mimicking peers. Hence, most of the covered domains have reached the middle level, with the domains of "self-care", "communication" and the domain of community skills scored highest averages in the tool. Intellectual disabled persons require more effort than others to acquire the skills that help him to rely on themselves and keep up with their fellow students. Another point is the chance of interaction with students gives them the opportunity to express themselves in a proper manner. Besides, presence of other students through various activities led to reduction of emotional behavior that may lead to self-harm or others and the many benefits of teamwork added to acquired skills they enjoy in all activities provided at public schools.

On the other hand, the score of "health and safety" achieved low. This could be referred to fact that public schools may overlook some of the things that may negatively affect student with disabilities in terms of environmental and public safety and accessibility as such environment was often not designed in first place to account for Individual differences of students, especially in play domains and outdoor spaces in the school.

- The second question states: What is the level of performance of students with mild intellectual disabilities at special education centers on the Adaptive Behavior Scale from their teachers point of view?

To answer this question, the arithmetical averages and standard deviations of the level of performance of students with mild intellectual disabilities in special education centers were calculated on the Adaptive Behavior Scale from their teachers point of view in general and for each domain of the study instrument. The findings show that level of performance for students with mild intellectual disabilities on the Adaptive Behavior Scale from the point of view of their teachers was low, and the domains of the research instrument in the middle and low levels, the averages ranged between (1.36- 2.62). The domain of "leisure and play management" came first with average level. "health and safety" came in second with averge level, the third was "self-care" with average as well. "communication" came forth with average. In the fifth place, the domain of "school life" at a low level. In the sixth place was the "socialization skills" with low level. In the seventh place, the domain of "selfdirection" came with low level. The "academic" came last with low level.

This may be attributed to the fact that the services provided to students in the centers at the socialization level are still below the required level as well as the lack of care by workers in the domain to provide special programs to help students with intellectual disabilities to improve their lives and raise their efficiency to participate in the development of society, all added to lack of opportunities available to them to work with individuals in larger society outside the center. This also may be referred to the fact that teachers in these centers have not received adequate training or that their plans and curricula in the centers lack the development of these skills, They are interested in training them in different skills that increase their adaptability to the surrounding environment, as well as the attitudes of their employees that may not be positive enough which may lead to a lack of socialization skills among these children.

The results of this study were inconsistent with the results of the (Adeniyi and Omigbodun, 2016 study) which indicated that the impact of classroom-based intervention on the socialization skills of students with intellectual disabilities in a school for people with intellectual disabilities on the socialization skills curriculum has significantly improved Socialization skills for students with intellectual disabilities who participated in their study.

Discussion of the results of the third question, which states: Are there statistically significant differences in the performance levels of students with mild intellectual disabilities on the Adaptive Behavior Scale based on the type of school variable (who are included in public schools and those in special education centers)?

A calculation of the means and standard deviations of the level of performance of students with mild intellectual disabilities were calculated on the Adaptive Behavior Scale based on school type variable (included in public schools and those in special education centers) and the (t-test) was applied. The results show that there were statistically significant )at $(\alpha \leq 0,05)$ for the level of performance of students with intellectual disabilities on the adaptive behavior scare according to the school type variable (included in public schools and in special education centers) where the difference was in favor of the included students In public schools when compared to other group in special education centers in the overall degree of the domains, except for the sub domain of "health and safety" and the sub domain of "leisure and play management" where the difference in these domains 
for came for the benefit of special education centers when compared to public schools as per their higher averages.

These differences may be attributed to the benefit of students who are included into public schools rather than education centers due to nature of the school environment where it imposes certain tasks in or outside the classroom. The nature of the relationship of the student with intellectual disabilities with his peers and teachers is also evident in the school environment which provides dealing with larger numbers of people than those within the special education centers. Hence, providing opportunities to deal and share unlimited social models, compared to the socially limited environments within special education centers.

In addition, if we address the aspects of "self-care" skills, their superiority in this may be due to the nature of the tasks carried out within public schools. They normally focus on teachers' tutoring and teaching a greater number of students. The nature of this kind of tutoring compels students to tackle the assigned tasks themselves and to adapt, which drives them to develop naturally on their own.

These differences may be due also to the supposed benefits of inclusive education for students with intellectual disabilities who will return results after their inclusion such as opportunities to model and adapt acceptable behavior from their fit peers, thus increasing their social competence and improving their overall behavior. Inclusion will also allow them to increase contact opportunities with more peers at school. This conclusion is consistent with (Fisherand Meyer's, 2002) study, which noted statistically significant differences in favor of the included students group where they have achieved higher socialization efficiency scores than the group of students in isolated special education centers who achieved few social gains.

The results of the study opposed (Hardiman et al., 2009) which showed that the results of included students' performance did not differ significantly from those of children in separate schools on most socialization domains of the scale.

The differences in the academic aspect for students in public schools may also allow for the conclusion that students with intellectual disabilities inclusion provides a wide range of learning opportunities and the development of academic skills. Recently, attention has been focused on teaching basic academic skills (reading, writing, And account) and to providing teachers teaching strategies that accommodate these students, in addition to the development of aspects of self-confidence and compassion and responsibility. This conclusion is consistent with the results of the (Vishwakarma and Pal, 2016) study which indicated that the average performance of students on academic skills at schools is better than for students in special centers.

In terms of the differences in the "communication" aspect of the integrated students, it can be explained similarly of explaining the social aspect. It can be referred to the opportunities for greater and more successful communication among students in the general school environment compared to special centers which allow for better and wider learning and development. The results of the study were consistent with those of (Al-Akhzami et al., 2013), which indicated that there were statistically significant differences in language and communication skills for the included students in all "socialization" skills that was referred to inclusion.

In terms of "community skills", the results of the study showed that they were higher among students with intellectual disabilities included at schools compared to special education centers. This finding was consistent with (Nota et al.,2007), which indicated that individuals with intellectual disabilities who attended school has shown greater independence skills and "self direction" in their daily activities, and the basic socialization skills associated with membership in groups are higher than of those in isolated special education centers. The findings also goes along (Lanfranchi and Vianello, 2008) study that showed that children have outperformed in the adaptive behavior domains, specifically the domains of communications" and "socialization") which the researchers attributed to the inclusion of the majority of children with intellectual disabilities in schools in Italy.

In general, the results of the study on communication and the academic domains were consistent with (Buckley et al., 2009) which indicated that there were significant gains in the communication, reading and writing skills, the daily life and behavior of included students in general classroom settings compared to those in the special education classes. These results contrast the study of (Hardiman and Fitzsimons and Guerin, 2009), whose results revealed that the efficiency of students of integration classes with intellectual disabilities did not differ from the efficiency of students of special education classes on most Adaptive Behavior Scale domains.

\section{Recommendations}

- The two researchers recommend conducting further studies that deal with other demographic variables, as well as making comparisons between students in special education centers and students in public schools.

- Provide courses for staff and workers with students with intellectual disabilities to promote them academically, socially and aim to develop community and academic skills in order to raise the socialization self-sufficiency for them in life.

- Invite researchers to collaborate with teachers to propose training programs that improve the adaptive behavior of students with intellectual disabilities to ensure that they can benefit from learning in less restrictive educational environments in order to achieve the desired goal of the philosophy of comprehensive social 
integration.

\section{References}

Al-Ajmi, N. and Al-Asaif, E. (2013), The parents' attitudes toward integrating pupils with intellectual disabilities with their children in regular schools. International Specialized Educational Journal, 2 (4), 316-345.

Al-Akhzmi, M. and Sulaiman, N. and Al-Shirawi, M. (2013), The difference in language skills and social interaction among mentally disabled children. Journal of Arab Childhood, 15 (57), 43 - 76.

Al- Ali, S. (2010), Jordanian Image of the Adaptive Behavior Assessment System in its second edition (ABAS-II, 2003): The image of teachers for the age groups (6-15 years). Unpublished PhD Dissertation, the University of Jordan.

Al-quraini, T., \& Gut, D. (2012). Critical components of successful inclusion of students with severe Disabilities- literature review. International Journal ofSpecial Education, 27(1): 1-18.

Al-Saree', I. (2014), Evaluation of programs and services for children with intellectual disabilities and autism disorder in light of Jordanian quality standards. Al-Manara Magazine, 20 (2b), 9-27.

Alwell, M. and Cobb, B. (2009), Functional Life Skills Curricular Interventions for Youth with Disabilities A Systematic Review Career Development for Exceptional Individuals.32(2):82-93.

Ashby, C. (2010). The trouble with normal: the struggle for meaningful access for middle school student with developmental disability labels. Disability and Society, 25(3): 345-358.

Bakhsh, A.(1999), Effectiveness of a proposed training program for the performance of various activities on the development of social skills for mentally disabled children who can learn. Journal of the Faculty of Education, 10 (1), 254-299.

Buckley, S.J., Bird, G., Sacks, B. and Archer, T. (2009). A comparison of mainstream and special school education for teenagers with Down syndrome: effects on social and academic development. Down Syndrome Research and Practice, 9(3): 51-67.

DelaVega, R., Ruíz, R., De la Rocha, M. and Jesús, O. and Rivera, O. (2013). Adaptive behavior and paddle tennis: A case study of down's syndrome. Advances in Physical Education, 3(4):187-189.

Felce, D., \& Perry, J. (2009). Living with support in the community: Factors associatedwith quality of life outcome. In S. L. Odom, R. H. Horner, \& M. E. Snell (Eds.), Handbook of Developmental Disabilities, New York: Guilford. 410-428.

Fisher, M., and Meyer, L. (2002). Development and social competence after two years for students enrolled in inclusive and self-contained educational programs. Research and Practice for Persons with Severe Disabilities, 27:165-174.

Hardiman, S., Guerin, S., \& Fitzsimons, E. (2009). A comparison of the social competence of children with mild intellectual disability in inclusive versus segregatedschool settings. Research in Developmental Disabilities, 30, 397-407.

Jarrar, A. (2012), procedures for integrating special needs in regular schools. Arab Childhood, 14 (53), $116-122$.

Jones, J., Kuntz, H., Vilela, T.\& Brown, H. (2008). Attitude of Community Developmental Services Agency staff toward issues of inclusion for individuals with Intellectual Disability. Journal of Policy and Practice Research in Intellectual Disabilities, 5(4): 219-229.

Khatib, J. (2010), Introduction to Intellectual Disability. i (1), Amman: Dar Wael for Publishing and Distribution.

Lanfranchi, S. Vianello, R. (2008). Genetic syndromes causing mental retardation: Deficit and surplus in school performance and social adaptability comparedto cognitive functioning. Life Span and Disability, XII: 4152

Larson, S. and Lakin, C. and Hill, S. (2012), Behavioral outcomes of moving from institutional to community living for people with intellectual and developmental disabilities: U.S. Studies from 1977 to 2010. SAGE Journals, 141: 49-71.

McIntyre, D. (2009). The difficulties of inclusive pedagogy for initial teacher education and some thoughts on the way forward. Teaching and Teacher Education, 25(4): 608-613

Nasser, I. (2004). Introduction to Education, Dar Ammar for Publishing and Distribution: Amman.

Nota, L. Soresi, S. Wehmeyer,M. Ferrari, L. (2007),Self-determination, social abilities and the quality of life of people with intellectual disability.Journal of Intellectual Disability Research, 11(51):850-865.

Omigbodun, and O.Adeniyi, Y. (2016),Effect of a classroom-based intervention on the social skills of pupils with intellectualdisability in Southwest Nigeria. Child Adolescent Psychiatry Mental Health.3, (16): 1029.

Santos, S. and Morato, P. and Luckasson, R. (2014), Psychometric Properties of the Portuguese Version of the Adaptive Behavior Scale. Intellectual and Developmental Disabilities. 5(52): 379-387.

Sharif, N. and Abdel-Halim, N. and Abdel-Aal, S. (2015). The effectiveness of the program of activities based on mental images in the development of belonging in intellectually disabled children who can learn in light 
of the systems of integration and isolation. Journal of Educational Sciences. 1 (2).

Vianello, R. and Silvia, M. (2011), Positive effects of the placement of students with intellectual developmental disabilities in typical class. Life Span and Disability. XIV (1): 75-84.

Vishwakarm, B. and Pal, S. (2016). A comparative study between integrated and inclusive

school in academic competency of children with mild mental retardation. International Journal of Multidisciplinary Research Review. 1, (1): 217-220.

Woolf, S. and Woolf, C.and Oakland, T. (2009),Adaptive behavior among adults with intellectual disabilities and its relationship to community independence intellectual and developmental disabilities. Intellect Dev Disable.48(3):209-215. 